\title{
Finding and Managing Information: Generic information literacy and management skills for postgraduate researchers
}

\author{
Heading $^{1}$, D., Siminson ${ }^{2}$, N., Purcell ${ }^{3}$, C. and Pears ${ }^{4}, R$. \\ ${ }^{1}$ Information Technology Service, Durham University, Science Laboratories, South Road, Durham, \\ DH1 3LE UK david.heading@durham.ac.uk; ${ }^{2}$ Mimas, 5th floor, Roscoe Building, The University of \\ Manchester, Oxford Road, Manchester, M13 9PL (present address - formerly Durham University \\ Library, Durham University, Stockton Road, Durham, DH1 3LY UK); ${ }^{3}$ Durham University Library, \\ Durham University, Stockton Road, Durham, DH1 3LY, UK; ${ }^{4}$ Durham University Library, Durham \\ University, Stockton Road, Durham, DH1 $3 L Y, U K$.
}

\begin{abstract}
A gap in the linking of information literacy skills and bibliographic software usage was identified in the postgraduate researcher cohort. While the provision was available, many researchers were not integrating the finding of research information and the management of that information using bibliographic software tools. This article describes the linking of these two areas in two courses presented to postgraduate researchers and analyses the feedback from those who attended. Overall, an overwhelmingly positive response was found. Most positively received was the software training, perceived as a 'new' skill, while information literacy skills were less well received, due mainly to the perception of those skills as already acquired.
\end{abstract}

\section{Introduction}

This paper reports on information literacy and management skills training aimed at doctoral students beginning their research careers. This training was part of an overall suite of packages of training delivered in academic years 2007/8 and 2008/9. The courses were developed within the UK Roberts funding remit (Roberts, 2002).

The courses arose from a realization that training postgraduate researchers in using bibliographic software management tools alone was insufficient to equip some of them to start an independent literature review or search. While training in Endnote, the facilitator found that while many students had heard of some online database resources, this knowledge was, in general, incomplete and patchy. For example, some students had used Web of Knowledge but were unaware of more specialized subject specific databases, while for others the situation was more or less the other way around.

The second issue relates to the Joint Skills Statements of the UK Research Councils (UK GRAD and UK Research Councils, 2001). Section C3 of this statement requires research students to be able to 'identify and access appropriate bibliographical resources, archives, and other sources of relevant information.' Section C4 requires students to be able to 'use information technology appropriately for database management, recording and presenting information.'

While a generic course cannot cover all possible sources of information, the above suggests strongly that an integrated approach to both accessing bibliographic 
resources, which are often in electronic format, and managing the references to those resources using bibliographic reference management software would be an appropriate and helpful approach.

The University Postgraduate Training Team includes specialists from both the university library and the information technology service. Within this team, therefore, two courses were devised to train students starting their research in using both bibliographic software and devising and using searches with online resources. A further advantage of this approach was considered to be the relative unpopularity of pure information based courses when compared to courses based around bibliographic reference management software. While the experience of delivering the latter courses suggested a need for a higher level of information literacy among participants, the uptake on the information literacy courses offered was relatively low. The courses were designed to integrate use of bibliographic resources, particularly those found online, and reference management software, specifically in this case, Endnote (Thomson Scientific, 2009). The courses analysed ran between October 2007 and May 2009, over 2 academic years. 19 sessions of the basics course and 13 sessions of the advanced courses are included in the analysis. The course outlines are detailed below (Section 2). Initial participant response was collected via an online survey form, and is analysed in Section 3.1. Some longer term impact assessment was undertaken using focus groups and student annual reports. These were focused more generally on the researcher training programme rather than specifically on the finding and managing information courses, but some indications of impact were gleaned. 


\section{Course Outlines}

For convenience, the course was divided into two parts - described as 'basic' and 'advanced'. Both ran for approximately three hours, inclusive of a break. The format for the workshops were the same, and consisted of a number of sections of input from library or information technology staff interwoven with hands on practise for the workshop participants, during which time the facilitators were available to answer questions.

The basic course started with an introduction as to what the terms finding information and managing information mean. The first major section is concerned with developing search strategies by extracting keywords and their synonyms from research questions or project titles. This is a pencil and paper based exercise using a grid to enable participants to design a search strategy for their own project.

The next stage is to introduce participants to the use of library catalogues. Although many of the participants have already encountered such tools, it is important to provide a common basis for moving forward, although this area attracted some criticism in participant feedback (Section 3.1). This section covered the university online catalogue and databases with a wider remit such as COPAC and WorldCat, and also the university document delivery service (inter-library loans) and the SCONUL access scheme for researchers accessing resources from other institutions. During the hands on time the students are encouraged to start seeking information for their own projects, using the results of the search strategy exercise outlined above.

The first part of the information management strategy is then introduced, with a very basic introduction to using Endnote, the bibliographical management software. This is demonstrated using the Endnote online search capability to the university library catalogue, retrieving the reference information of the items the participants have, hopefully, recovered during the previous hands on time. The software is introduced to the participants, the search capability demonstrated and the participants are then given time to practise the retrieval of references. At times, participants have requested a demonstration of retrieval of references directly from the library search results to the software, avoiding the use of the in-built Endnote search tools. This has been done either to the whole workshop or on an ad-hoc basis to individuals, although the process is described in the later retrieval from online databases section. After a break, online databases related to journal articles are introduced. This is achieved using a generic database (Web of Knowledge) and also a subject specific one (International Bibliography of the Social Sciences (IBSS)). The aim is to both familiarize students with the range of databases and their limitations in terms of coverage, as well as the range of user interfaces that researchers are faced with. A number of demonstration searches are carried out using these databases. After these demonstrations, the interface with Endnote is demonstrated, downloading the results of the searches to the reference library.

Some hands on time is then allocated, during which participants may ask about subject specific databases. The next issue addressed is, very briefly, the need to use referencing and avoid plagiarism. Although plagiarism is a major issue in higher education, the point is made to students so often that it loses its edge in this context. Other courses cover the issue of plagiarism in much more depth, and student feedback indicated that they felt that the coverage was repetitive and too brief, so this issue is only discussed by way of an introduction to the use of Endnote in combination with Microsoft Word for referencing a research document. 
The demonstration of referencing shows how various items are referenced, how the software understands repeated citations and handles the removal of items from the text. The changing of the citation style from author - date to numbered and back again is also shown.

After some hands on time, the session is wrapped up by asking the participants to fill in an online feedback form, and the advanced session is advertised.

The advanced course builds on the previous course, although the earlier course is not specified as a prerequisite for those booking on the advanced course. The advanced course starts with an overview of the basics course contents, designed to ensure that all participants are aware of the level at which the course will commence. The bibliographic part of this overview includes adding documents to the Endnote library references as an information management technique, and also information on the major cause of problems with Endnote references in Word documents, which is the revealing of field codes in the document.

The first part of the advanced course demonstrates further search techniques. This mainly focuses on cited reference searching through Web of Knowledge, but also includes journal impact factors. This latter part caused some problems as it is not particularly relevant to participants from the arts and humanities, but it is useful to social scientists and scientists.

The next part of the course is a change in pace, as it looks at an online version of the software, Endnote Web. This digression is aimed at providing researchers with knowledge of the tools available if they are working away from the university or do not have access to the software on their own computers. It also provides facilities for sharing Endnote libraries, for example, with undergraduate students in seminar groups. A number of students do sign up for the service during the session, although some feedback suggests that this section is not regarded highly by some of the participants.

Scholarly communication is covered next. Access to theses, both UK and international is discussed along with conference proceedings and open access electronic repositories. Various databases are covered in this section such as Index to Theses, WorldCat dissertations and institutional repositories. Conference proceedings, covered via Web of Knowledge, are becoming so integrated with the normal cataloguing of articles that this section ran a danger of being a repeat of part of the basics course. Scholarly communication was followed by a break.

The final section of the course was divided into two parts. The first section discussed styles of referencing and how to change and modify the styles in Endnote to fit the styles required by a journal article or thesis. The aim of this section was not, particularly, to enable participants to edit styles for themselves (which is quite a difficult task) but to make them aware of the styles already available, and some of the pitfalls which can make bibliographic references appear without the correct information in the document. For example, a newspaper article used with a style which has no definition for that reference type will display it as a generic reference type, and hence much of the information will be missing.

The last part of the course dealt with techniques of keeping up to date with the literature. It covers email alerting services and save searches, for example on ZETOC and Web of Knowledge, and also describes and demonstrates the use of RSS feeds for similar purposes. This section was followed by some hands on time and then a wrap up session where the students were encouraged to give feedback on the workshop on an online form. 


\section{Assessments}

A framework for assessing the impact of postgraduate training in the UK has been put forward by the 'Rugby Team' (The Rugby Team, 2008). This identifies five levels of impact: foundations, reaction, learning, behavior and outcomes. We note that evaluation becomes harder as this list is ascended. The Finding and Managing Information sessions were all finished by inviting participants to fill in an online feedback form. This would correspond to level 1 of the impact framework, assessing the reaction of the participants to the workshop. This feedback is discussed below (Section 3.1). Further evaluation of the impact of the workshops is hampered by the difficulty of following up a specific group of students within a disparate cohort. Two channels for the assessment of longer term feedback and impact were identified within the overall feedback mechanism of the postgraduate programme within the university. These, student annual reports and end of year focus groups, would provide evaluation information at levels 2 (learning) and 3 (behavior) of the impact framework. This is discussed in Section 3.2.

\subsection{Immediate Feedback}

In all, 348 students attended the basics courses in 19 sessions, of which 211 filled in the 'happy sheet', a $60 \%$ return rate. 224 participants attended the advanced courses in 13 sessions, of which 136 returned feedback, also a return rate of $60 \%$. The completed feedback forms, which were in electronic format, were analysed using the qualitative analysis software NVivo (QSR International, 2008).

\subsubsection{The Basics Course}

The immediate feedback was analysed separately for the basics and advanced courses. The feedback form questions for the basics course are listed in Table 1.

1. How would you rate the workshop overall? $(4=$ high, $1=$ low $)$

2. Was the workshop at the right level for you?

3. What did you think to the overall length of the workshop? $(5=$ too long, $1=$ too short)

4. Was the amount of information provided before and during the workshop appropriate? $(5=$ too much, $1=$ too little)

5. How confident did you feel about finding information for your research BEFORE today's workshop? ( 4 = very confident, $1=$ not at all confident)

6 . How confident do you NOW feel about finding information for your research? $(4=$ very confident, $1=$ not at all confident)

7. What did you like most / find most useful about the workshop?

8. What did you like least / find least useful about the workshop?

9. In what way(s) do you think today's workshop will make a difference to your research?

10. What did you think of the format of this workshop, with its mix of demonstrations, hands-on time and individual support?

11. Which style of learning do you prefer?

12. Is there anything you would like us to change or add to the workshop? If so, please indicate in the box below.

13. Would you recommend today's workshop to your friends or colleagues - and why / why not?

14. Do you have any other comments?

Table 1: Feedback Questions for Basics Course 
The feedback analysis focused on questions 1-3 and 5-8. The earlier questions were, broadly speaking, numerical, and so can be analysed statistically. The results of the statistical analysis are shown in Table 2.

\begin{tabular}{|l|l|l|l|}
\hline Question & Range & Average & Standard Deviation \\
\hline 1 Overall Rating & $1-4$ & 3.5 & 0.6 \\
\hline 3 Length & $1-5$ & 3.5 & 0.7 \\
\hline $\begin{array}{l}\text { 5 Confidence } \\
\text { Before }\end{array}$ & $1-4$ & 2.5 & 0.8 \\
\hline 6 Confidence After & $1-4$ & 3.5 & 0.5 \\
\hline
\end{tabular}

Table 2: Basic Course Feedback Results from Numerical Questions

It is instructive to examine the variation of some of the results against time. The overall rating against time is shown in Figure 1. This shows an initial flurry of variation in the average ratings, as the facilitators learnt how to present the material. It also shows that the later presentations kept up the overall ratings of the earlier sessions, in spite of a change in facilitators between the 2007/8 and 2008/9 academic years.

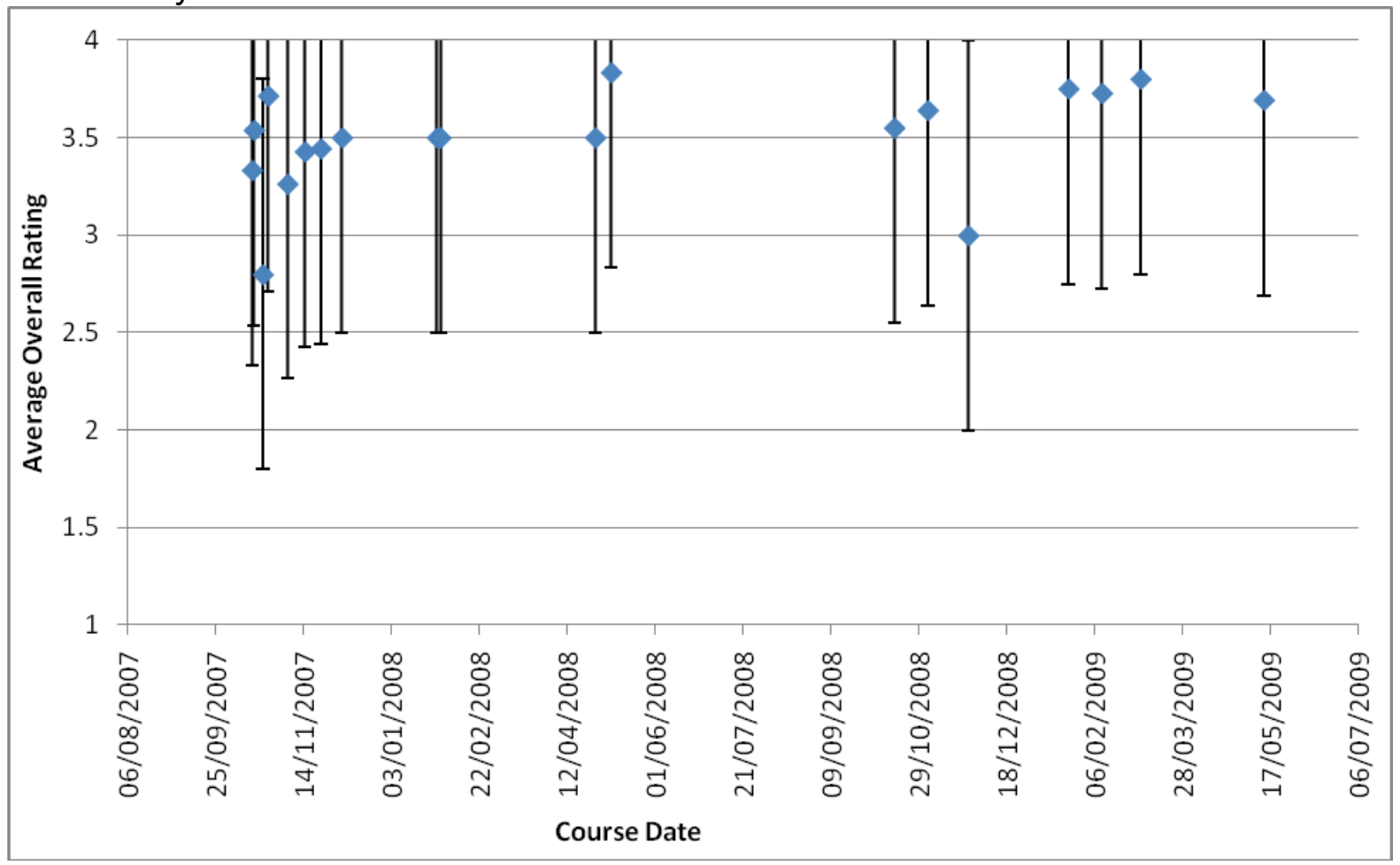

Figure 1: Basics Course Overall Rating Average and Standard Deviation against Time

The length of the course, at just less than 3 hours, was generally regarded as being about right. Some comments were made that as the respondent already knew some of the material, the course could have been shorter. However, many thought that the length was 'just right', and the issue of some participants already knowing some part of the material presented is a common problem with introductory courses. Overall, the length of the course seems to have been about correct to allow plenty of hands on time as well as sufficient depth in the presentations to engage most of the participants. 
The change in participant confidence level in finding relevant research information is measured by a combination of questions 5 and 6 . The averages (Table 2) indicate that overall confidence level of participants increased by approximately 1 on a scale of 1 to 4 . The individual increases are plotted on Figure 2. This shows that the overall increase for over $50 \%$ of the participants was indeed 1 , while $23 \%$ felt their confidence had increased by 2 levels and $20 \%$ had experienced no change. The bulk of those who reported no change also reported high levels of confidence before the course.

A small number of participants felt that their confidence had fallen as a result of the course. Correlating these with written comments by the participants indicates that previously they had not been aware of the range of information available. One participant noted that they had found 'a lot I didn't know I didn't know'. This thus must count as a positive learning outcome, even though the numerical result might at first sight appear disappointing.

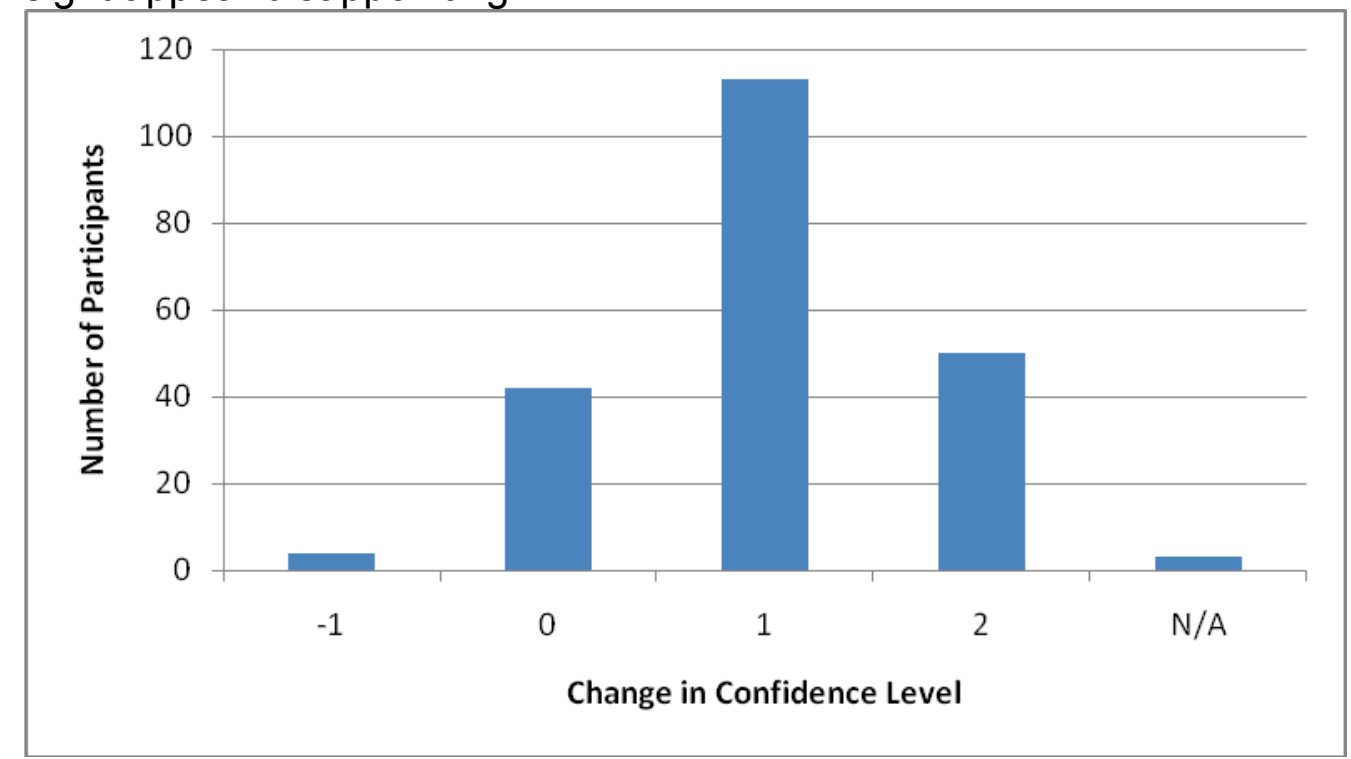

Figure 2: Responses to Q6 - Q5.

The responses to questions 7 and 8 were written, and were analysed using the qualitative analysis software NVivo 8 . Each received response (not all students gave responses to all questions) was coded to nodes most representative of the comment. The coded responses could then be examined for the comments of the participants representing the various areas of the course. 


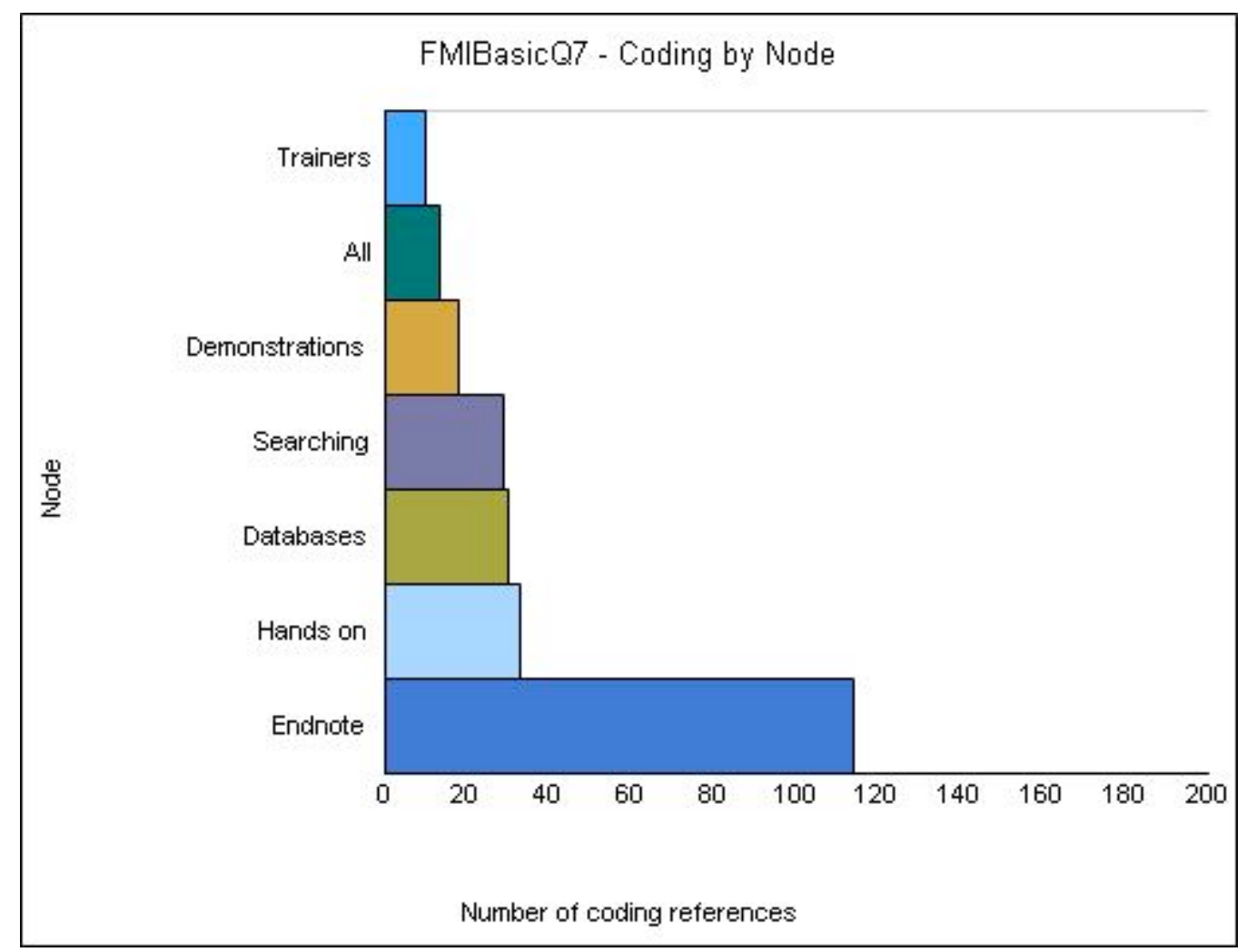

Figure 3: Analysis of Basics Course Q7

The analysis of question 7, 'what did you like most about the course?' is shown in Figure 3. This shows that, overwhelmingly, the information presented about Endnote was the most popular, although some participants recognized the importance of the search strategies input and the information on databases. A number of participants commented on the nature of the course, such as the hands on time, trainers and demonstrations rather than the course content.

The responses to question 8, 'what did you like least or find least helpful about the course?' produced a much more diverse set of results. The top ten nodes of the analysis are shown on Figure 4. This shows that the overwhelming response to the question was to report that nothing was unhelpful or not liked within the course. After this, the description and demonstration of the library web site and catalogue received some criticism. The rest of feedback was a general assortment of comments that the course was both too fast and too slow, and similar themes which do not really make for a coherent critique of the course. 


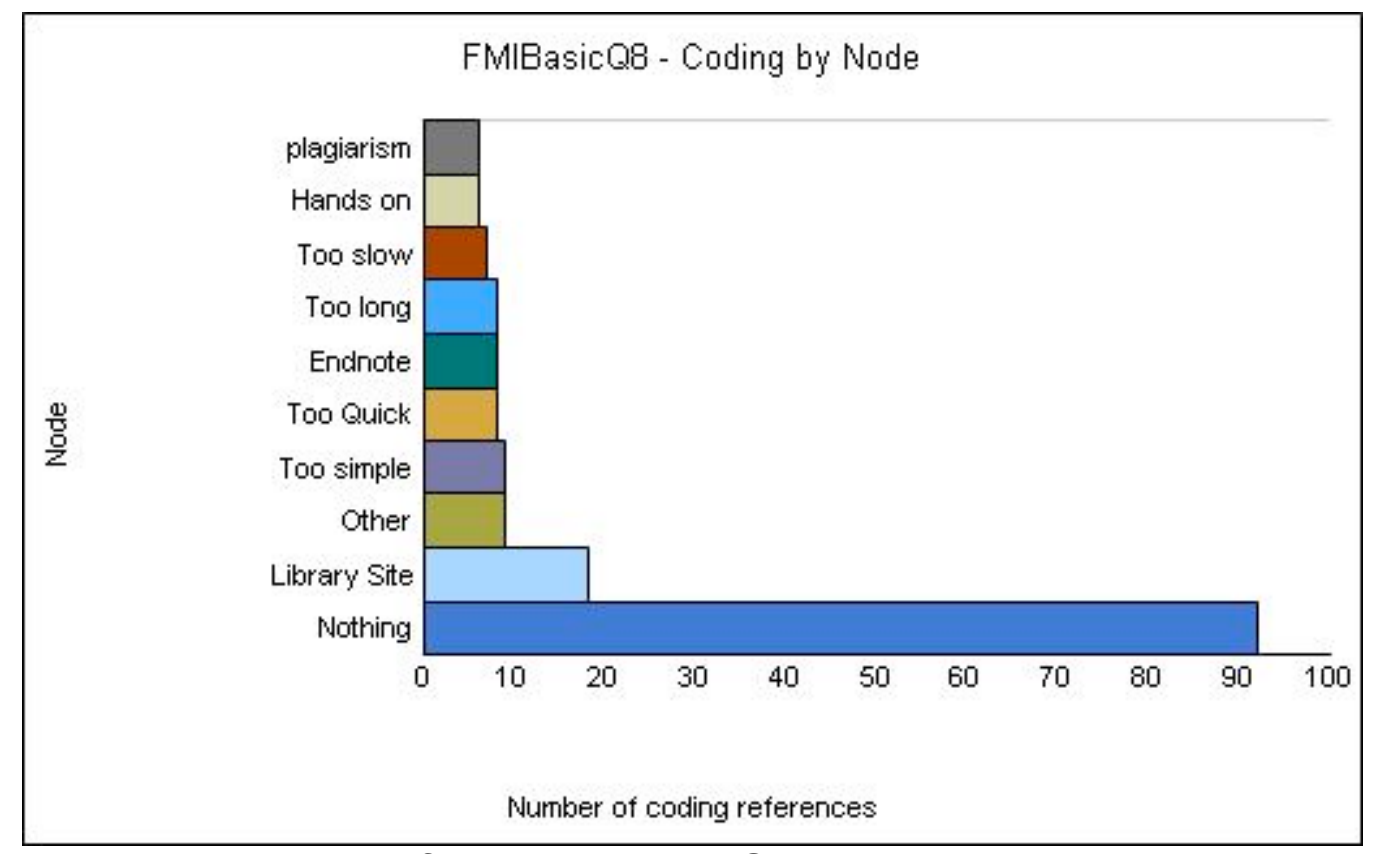

Figure 4: Analysis of Basics course Q8

With the criticisms of the library web site, we can see how the facilitators responded to the feedback on this aspect of the course content. The critical comments on the library web site are plotted against the dates of the course presentations in Figure 5. This shows that after an initial flurry, the negative comments died down as the presentation was modified by the facilitators. At the end of the academic year, the library facilitator changed, and the new facilitators ran the course from the original notes, yielding another spike in the comments which then died down as the new staff adjusted their presentation accordingly.

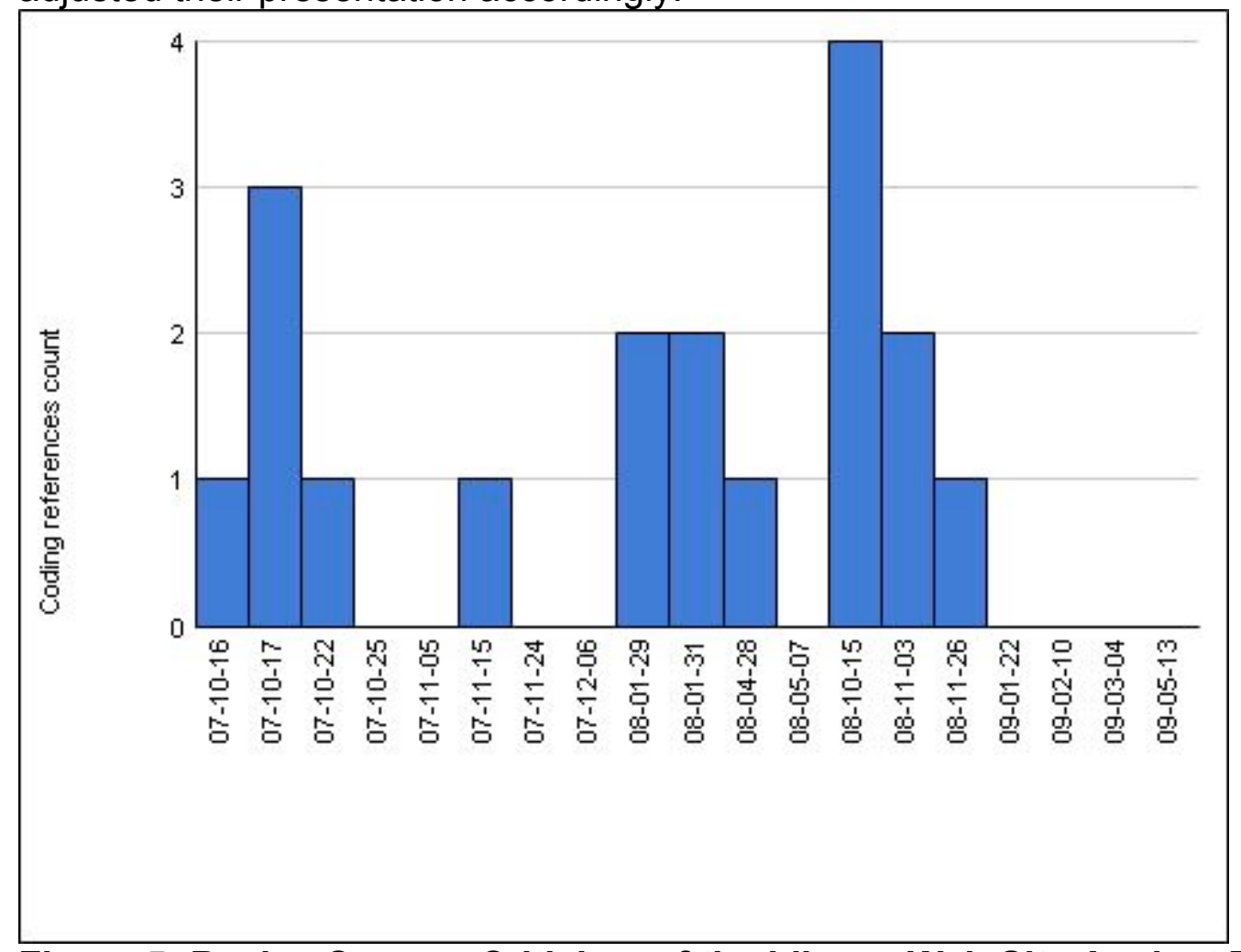

Figure 5: Basics Course: Criticism of the Library Web Site Against Time 


\subsubsection{The Advanced Course}

The questions used for the advanced course feedback form are in Table 3. The bulk of the analysis here presented focuses on questions 1 and 3-7.

1. How would you rate the workshop overall? $(4=$ high, $1=$ low $)$

2. Was the workshop at the right level for you?

3. What did you think to the overall length of the workshop? $(5=$ too long, $1=$ too short)

4. This course has improved my library and information searching skills. (4 = strongly agree, $1=$ strongly disagree)

5. This course has improved my EndNote skills. (4 = strongly agree, 1 = strongly disagree)

6. What did you like most / find most useful about the workshop?

7. What did you like least / find least useful about the workshop?

8. What else would you like the course to cover?

9. If you have also attended a "Finding and managing information... the basics" course - how do you feel today's advanced course built on the previous course?

10 . Would you recommend today's workshop to your friends or colleagues - and why / why not?

Table 3: Feedback Questions for Advanced Course

The averages for the numerical questions are shown in Table 4. These show that the overall rating and perception of the length of the course are, more or less, the same as for the basics course. 


\begin{tabular}{|l|l|l|l|}
\hline Question & Range & Average & Standard Deviation \\
\hline 1 Overall Rating & $1-4$ & 3.4 & 0.6 \\
\hline 3 Length & $1-5$ & 3.5 & 0.7 \\
\hline $\begin{array}{l}4 \\
\text { Information skills }\end{array}$ & $1-4$ & 3.4 & 0.7 \\
\hline $\begin{array}{l}\text { 5 Improved } \\
\text { Endnote skills }\end{array}$ & $1-4$ & 3.3 & 0.7 \\
\hline
\end{tabular}

Table 4: Advanced Course Feedback Numerical Results

Questions 4 and 5 attempted to establish the increase in skills the participants had obtained from the courses for information and bibliographic management skills respectively. Both results indicate that participants did find the course useful at enhancing their skills in these areas.

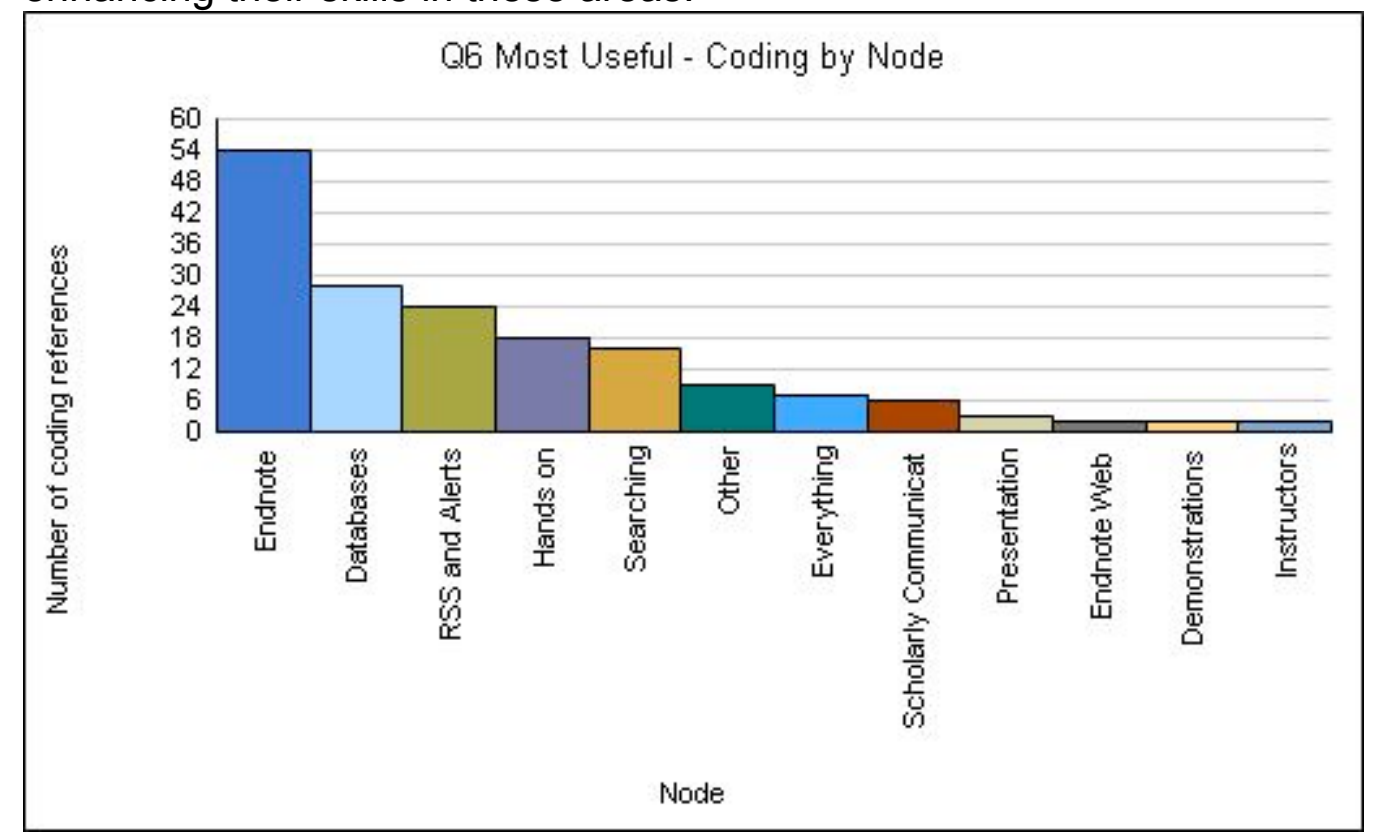

Figure 6: Advanced Course Most Useful Analysis

The analysis of the qualitative data in questions 6 and 7 was conducted in the same way as the basics course. The results for the most useful aspects of the course are in Figure 6. This shows, as with the basics course, that the Endnote bibliographic software training was the most popular aspect. However, the information literacy parts of the course, the discussion of various online databases and alerting services were, relatively speaking, more positively regarded than equivalent aspects of the basics course. This might show that these more advanced information literacy components are new to the wider range of participants, and aspects of information literacy which might be regarded as being more advanced than these would have to be carefully introduced. 


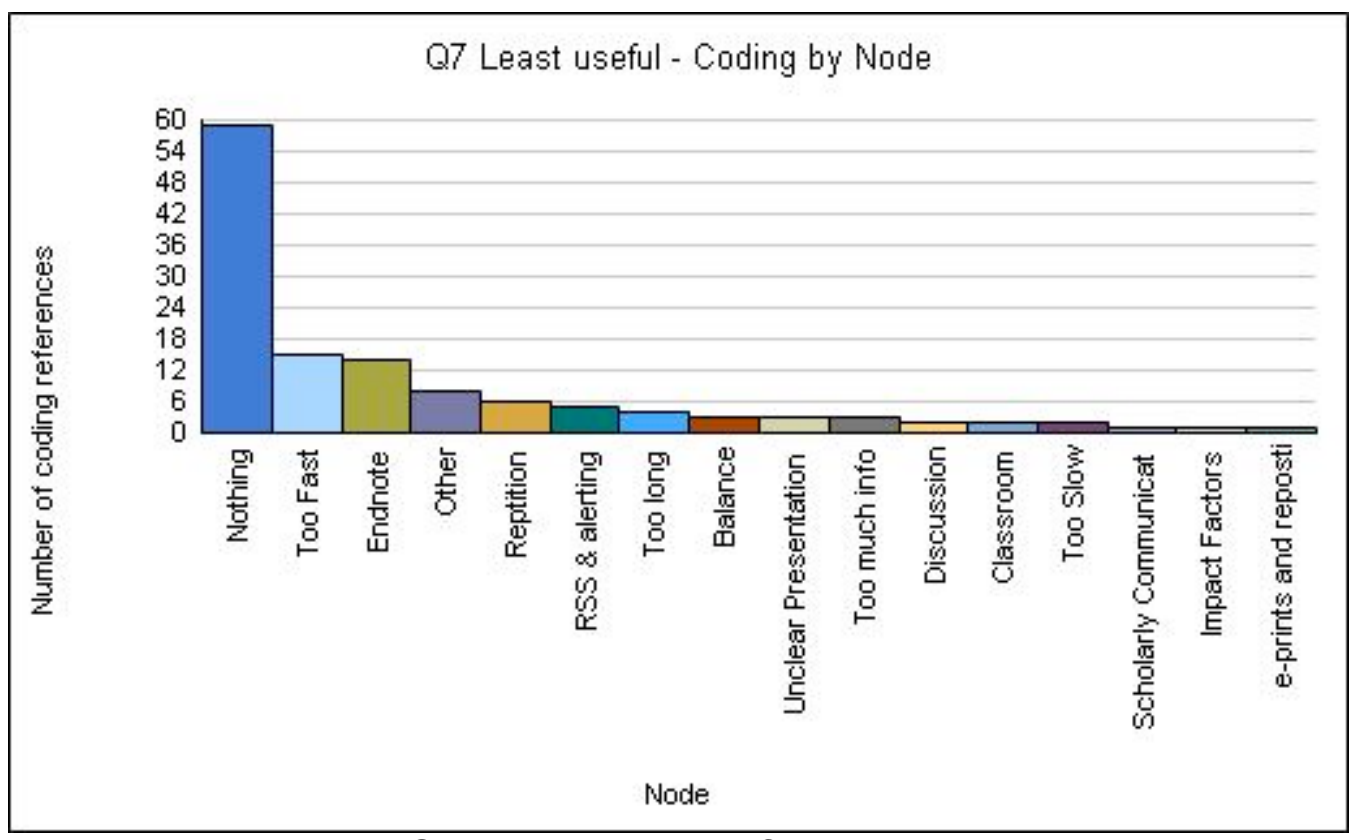

Figure 7: Advanced Course Least Useful Analysis

The analysis of the less useful course components reported in question 7 is shown on Figure 7. As with the basics course, the overwhelming majority of participants did not report any aspects of the course as not useful or disliked. The appearance of Endnote in the least useful top three might be a surprise, but it covers a range of comments, including the coverage of Endnote Web, the complexity of editing styles and complaints that the coverage was too simple for an 'advanced' course.

Of the 58 responses to question 9 , about the linkage of the advanced and basic courses, $49(84 \%)$ responded positively that the courses flowed together well, while $5(9 \%)$ responded negatively. 4 respondents made other comments which did not really answer the question. Of the 137 responses to question 10, asking if the participants would recommend the course to others, $93 \%$ responded positively while less than $4 \%$ were negative.

\subsection{Longer Term Impact}

The longer term impact of the courses has not been specifically assessed. Anecdotally, on a later course aimed at students using Word to write a thesis, most of whom had been on a Finding and Managing Information course, a straw poll indicated that roughly two thirds were using Endnote. This suggests that the penetration of Endnote into student work patterns is significant, but does not suggest directly that the Finding and Managing Information courses are responsible. Similarly, the recommendation of a final year student at an induction session that the new postgraduate researchers should get Endnote training as soon as possible is suggestive but not evidence for the success of the programme.

The postgraduate training team ran a series of three focus groups at the end of the 2008-9 academic year. 21 students attended, most of whom had participated in the Finding and Managing Information workshops. In response to the question 'Can you identify any particularly useful or not so useful workshops or resources?' Endnote and the Finding and Managing Information courses were identified as being useful 5 times, more than any other course. A total of 9 courses were identified in this way, out of a total of 150 different courses offered across the university. Two students 
commented that Endnote had changed the way they work. Only one student, however, specifically indicated that the Finding and Managing Information courses had been useful. While the sample is small and self-selecting, the implication of these responses is that the Endnote component at least of the course is having some effect.

The other channel within the university for feedback are annual reports, submitted by all students, which provide an overview of their research and training activities. Participation in the reporting is compulsory and is normally completed on time by over $80 \%$ of students. These are reviewed on a faculty basis and summaries made available to the postgraduate training team. The 2007-8 annual report reviews contain some specific comments about the Finding and Managing Information courses.

In the 2007-8 academic year, about $30 \%$ of students attended the Finding and Managing Information courses. The report from the Faculty of Social Science and Health refers to the courses as being 'very good' and also to Endnote specifically as 'good'. On the other hand the same report also contains the comment that the course was 'too basic'.

The report from the Faculty of Arts and Humanities also contains the comment that the course was a good one but that some components were familiar from undertaking a master's course. Again, the Endnote parts were identified as being particularly useful. Additionally, three comments were made that the Endnote training was useful, although it is unclear from the context if the reference is to the component of the Finding and Managing course which contains Endnote training, or the previous single session on Endnote training alone.

\section{Conclusions}

The courses were very well received. The evidence indicates that participants found the information literacy components of the courses useful. Much of the positive comment focused on the use of bibliographic reference management software. This would seem to be because many participants regarded themselves as being information literate, at least so far as library catalogues and generic database searches were involved. The introductions to a wider range of online repositories to search and to alerting services were better received, suggesting that these aspects of the workshops were regarded as new and useful by the participants.

The conclusion from this study is that integrating information literacy training along with training in use of bibliographic reference management software is a useful way of training researchers at the beginning of their work. While many students feel fairly confident about their ability to find relevant literature, having to think of key words and conduct real searches on their topic in a workshop enhances these skills as well as increasing the range of online resources of which the participant is aware. The coupling of this with the bibliographic software training ensures that the full power of both online resources and information technology are closely aligned. However, the overwhelmingly positive comments with respect to Endnote compared to the information literacy elements of the workshops suggest that students may regard them as 'carrot and stick' courses, where Endnote is the carrot and the information literacy components have to be gone through to get to the interesting parts.

Aside from the requirements of Roberts funding for courses to be presented in a generic manner, the numbers of participants may have precluded subject specific approaches anyway. Over the two academic years reported upon, over 400 students attended a Basics session, an average of around 19 per session. It would have been 
very intensive for the two facilitators to have presented to all of these students in a subject specific manner, as the average session size would have dropped due to diary clashes and the relatively small number of postgraduate students in some departments. Initially, faculty specific courses were offered, but participants preferred to attend a session convenient to them rather than adjust their diary to fit in a more specifically tailored course. The courses were, therefore, presented in a truly generic manner. Only two students commented about this aspect of the course, suggesting that it was too science focused, although the range of databases used in demonstration included both Arts and Social Sciences resources. It would appear that the negative comments made about the information literacy elements arose mainly from the assumptions made by students that they were already equipped for such activity.

As noted above, the hands on time enabled students to use subject specific resources, and they were encouraged to use such resources during these periods. In general, this caused little difficulty to the facilitators, who were usually able to advise on specific problems. Often, the participant observing the facilitators struggling with an issue gave the participant confidence that the issue was with the technology, not themselves. The use of subject specific databases by participants was encouraged and enabled them to tailor the training to their own requirements, suggesting that in this aspect, at least, we manage to obtain student based learning (Biggs, 2003, 24)

The integration of bibliographic reference management software training and information literacy training was the key idea behind these courses. In an increasingly integrated information environment the overlap between information finding and storage is becoming greater. Endnote itself is becoming more capable of searching online databases, and full text of journal articles, and the databases are integrating themselves more closely with reference management tools (Fitzgibbons and Meert, 2010). In these courses we did not wish to draw the distinction between the two areas, preferring to see them as complementary rather than separated. This seems to have worked well and participants saw and used an integrated search and storage approach.

Overall, the integration of information literacy and management software has worked very well. The information literacy elements of the course are currently being reworked, in the light of the above feedback, with some knock-on effects on the presentation of the management software. Further feedback and analysis along with developments in both software and online resources will, no doubt, require further refinement of the courses. 


\section{References}

Biggs, J. (2003) Teaching for quality learning at university, Buckingham, Society for Research in Higher Education and Open University Press.

Fitzgibbons, M. and D. Meert (2010) 'Are bibliographic management software search interfaces reliable?: A comparison between search results obtained using database interfaces and the endnote online search function', The Journal of Academic Librarianship, vol. 36, no. 2, pp 144-150.

QSR International (2008) Nvivo 8, http://www.qsrinternational.com/.

Roberts, G. (2002) Set for success, London, http://www.hmtreasury.gov.uk/ent res roberts.htm.

The Rugby Team (2008) The rugby team impact framework, www.vitae.ac.uk/rugbyteam. Thomson Scientific (2009) Endnote, http://www.endnote.com/.

UK GRAD and UK Research Councils (2001) Research councils' joint statement of skills training for research postgraduates, UK GRAD, www.vitae.ac.uk/jss. 